\title{
ISC Recull de premsa
}

2020

Ecoaula.es (2020). «Asociaciones de familias reclaman a Educación que siente las bases de una educación inclusiva en llengua de signos para el alumnado sordo». elEconomista, 30 de juny.

https://www.eleconomista.es/ecoaula/noticias/10636907/06/20/Asociaciones-defamilias-reclaman-a-Educacion-que-siente-las-bases-de-una-educacion-inclusiva-enlengua-de-signos-para-el-alumnado-sordo.html

Greugeon Plana, Bart; Enrech Calbet, Anna (2020). «Llengua de signes catalana, tan visual com invisible». La Directa, 18 de febrer.

https://directa.cat/llengua-de-signes-catalana-tan-visual-com-invisible/

\section{8}

Muñiz, Mar. (2018). «El dilema del bebè sordo: ¿Cómo enseñarle a hablar?». El Mundo, 11 de septiembre.

https://www.elmundo.es/papel/historias/2018/09/11/5b969od546163f9b9c8b45e2.htm 1

2016

Yo Apoyo al TEL. «¿Cómo dar visibilidad al TEL, si nadie lo conoce?». Yo Apoyo al TEL, 15 de setembre (en línia)

https://yoapoyoaltel.com/dar-visibilidad-al-tel/

2013

Roxby, Philippa. (2013). «The loneliness of Language difficulties». BBC News, 10 de novembre.

https://www.bbc.com/news/health-24851520

2008

Valenzuela, C. (2008). «Una propuesta para identificar e incrementar las habilitades narratives de los niños». El Pulso, 17 de octubre.

http://elpulso.med.uchile.cl/20081017/noticia2.html 